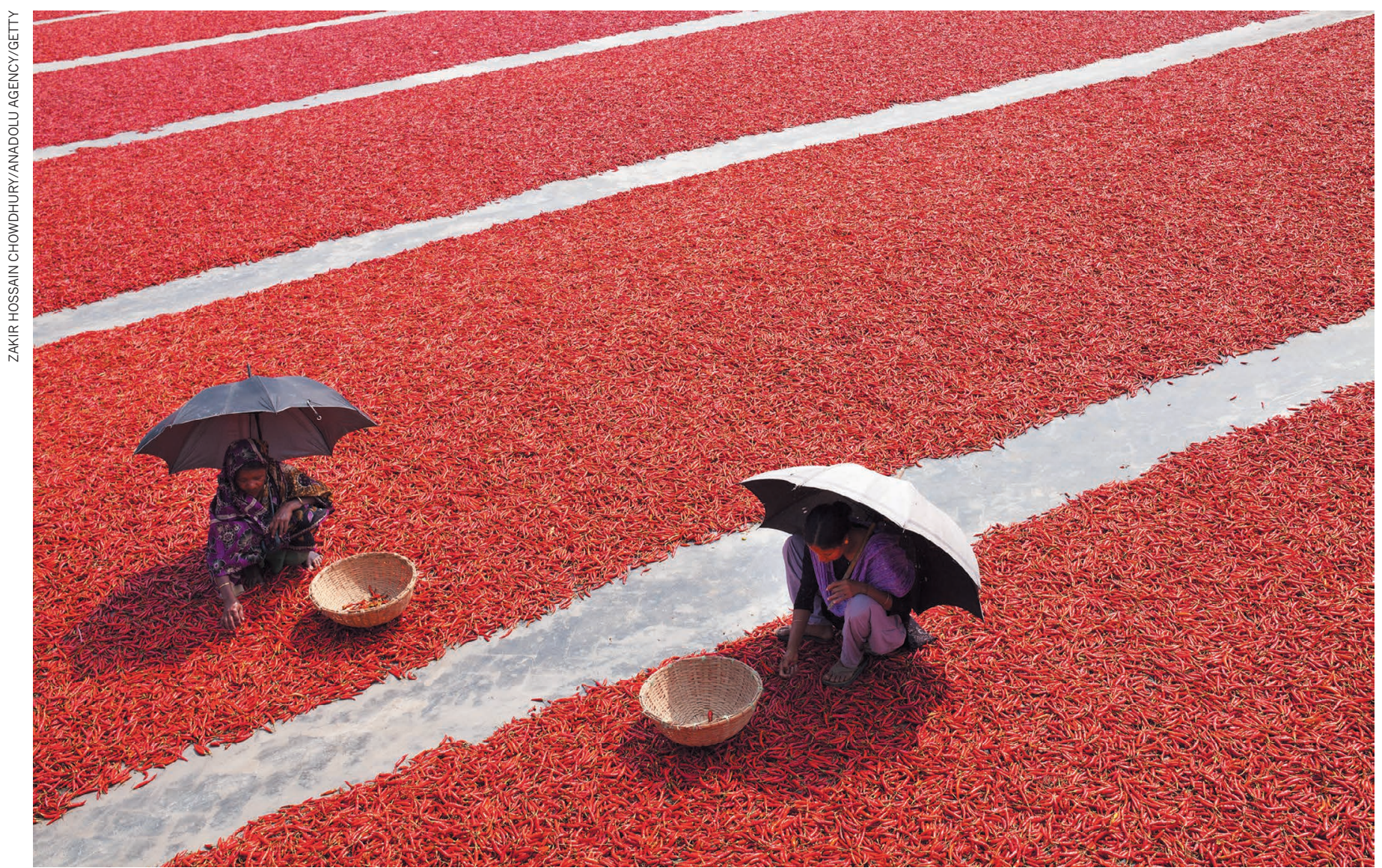

Drying red chillis under the sun provides one of the few sources of employment for women in an area of Bangladesh.

\title{
Fix food metrics
}

\section{For sustainable, equitable nutrition we must count the true global costs and benefits of food production, urge Pavan Sukhdev, Peter May and Alexander Müller.}

$\mathrm{C}$ urrent patterns of crop and livestock production and of processing, transport and consumption, are not delivering healthy, nutritious food to society. They are generating large and unacceptable impacts on the environment and on vulnerable populations.

Food systems are now the source of $60 \%$ of terrestrial biodiversity loss, $24 \%$ of greenhouse-gas emissions, $33 \%$ of soil degradation and $61 \%$ of the depletion of commercial fish stocks ${ }^{1}$. And the increasing homogenization of food sources worldwide is narrowing the genetic diversity in animals and plants that is crucial to secure human nutritional needs against climatic and other changes.

Food systems are undermining human health all over the world, by permitting, or even promoting, inappropriate diets or unsafe foods. As the Global Nutrition Report, released this September puts it: "Diet is now the number-one risk factor for the global burden of disease" ${ }^{2}$.
Around 800 million people in developing countries consume less than the 2,100 kilocalories per day recommended by the World Food Programme ${ }^{3}$ because of failures in access and distribution. At the same time, 1.9 billion people in the developed world take in more than 3,000 kilocalories per day ${ }^{4}$. As processed foods high in fat and carbohydrates come to dominate, even in developing nations, "the number of children under 5 who are overweight is approaching the number who suffer from wasting"

Yet agriculture employs around 1.3 billion people. Around 1 billion work on small farms ${ }^{5}$ (less than 2 hectares). Admittedly, their working conditions could mostly not be rated as 'decent' by the International Labor Organization's definition, but what are the chances that society could provide alternative employment to these people if their 500 million small farms gave way to concentrated, large-scale and highly mechanized agribusiness? The world is already short of about 200 million jobs ${ }^{6}$, and major industries such as steel and car making employ only 6 million and 9 million people worldwide, respectively.

Small-scale agriculture provides subsistence, employment and most of the food directly consumed by urban residents throughout the developing world. It also ensures that rural landscapes are conserved as a touchstone for cultural identity.

Current metrics for agricultural performance do not recognize or account for any of these costs or benefits. The emphasis on yields or profits per hectare is as reductive and distorting as is gross domestic product, with its disregard for social and natural capital. Food metrics must be urgently overhauled or the United Nations' Sustainable Development Goals will never be achieved.

\section{HOLISTIC EVALUATION}

We contend that a sustainable food system has three key attributes. It should deliver adequate nutrition and health across all 
levels of income and societal development. It should avoid significant negative ecological and environmental impacts. And it should ensure equitable access to land, water, inputs (such as seeds and fertilizer) and technical and financial assistance for the roughly 1 billion people who still depend on small farms for their livelihoods.

To achieve this, policymakers, researchers and citizens need more reliable and integrated information on the hidden costs and benefits - the 'externalities' - of the whole agrifood system, not just parts of it. A new project that aims to deliver such information was launched in October 2016 by The Economics of Ecosystems and Biodiversity (TEEB), a network of organizations that we are involved with. Called TEEB for Agriculture and Food (TEEBAgriFood), the project will attempt to provide a framework for a holistic evaluation.

Take, for example, maize (corn). The trend is to convert much of what is (over-) produced into starch and sugar. In conventional agricultural analysis, the improvements in yield per hectare per year in intensive maize-production systems are usually presented as the main indicator of success. More maize for fewer dollars up-front is also considered an important contribution to food security.

Of course it isn't that simple. TEEBAgriFood has analysed three different maize-production systems (intensive industrial, organic and traditional), looked at how the product of these different systems is used, and charted their impacts on ecosystems, biodiversity and human health. For example, increased production of maize in industrial systems has a clear link (through lower prices for high-fructose corn syrup) to the increased use of maize-based sweeteners in soft drinks, a significant driver of obesity and diabetes. According to the World Health Organization, the global costs of type 2 diabetes are more than US $\$ 850$ billion per year.

To evaluate maize holistically we should account for its market price, its contribution to health costs, the environmental impacts of increased greenhouse-gas emissions from mechanized farming and transport, and the impacts of fertilizer use on aquatic life. TEEBAgriFood hopes eventually to make all these links visible.

\section{POLICY PROBLEMS}

We have conducted other initial evaluations and policy analyses for agricultural systems producing rice, palm oil, livestock (including beef and dairy cattle, and also meat from chicken and pigs), inland fisheries and agroforestry systems. In each case, we have found the same sorts of policy failure, and problems with food security and nutritional quality. These problems cut across current commodity-production systems

at different scales - from smallholder to corporate farming - and along different commodity chains.

For example, significant costs are associated with the expansion of oil-palm plantations into tropical rainforests in Indonesia. This sometimes entails the draining of peatlands, which can then catch fire. The resulting health risks from air pollution are severe, especially for children and older people. According to the World Bank ${ }^{7}$, the disruption to economic activity in 2015 alone cost the Indonesian economy an estimated $\$ 16$ billion - more than the annual country-wide value added by palm oil.

Similarly, the externalities of soya bean production in tropical rainforests in the Brazilian Amazon were so damaging that they led to a boycott and the development of a certification scheme. In 2006, the Brazilian soya bean crushers' association decided to embargo purchases of soya beans from recently deforested areas; international and domestic non-governmental organizations served

"The emphasis on yields or profits per hectare is as reductive and distorting as is gross domestic product." as watchdogs to the spread of clearances. Supportive purchase policies by traders in Europe stimulated buyers to accept only rainforest-certified soya beans. Deforestation directly related to soya bean production has all but ceased (see go.nature.com/2gdrcqw).

We have found that there is a great deal of knowledge about the ways in which foods are produced and the inputs they demand. There is much less information about the impacts of these value chains on the environment and on social groups. Furthermore, our studies have generally not touched on what happens to these products once they leave the farm gate. TEEBAgriFood and others need to probe the relative impacts of different transport and processing pathways, and how options for food disposal at each stage of the supply chain and after consumption affect the human footprint on the planet. And more work is needed on the health risks of components of these food systems.

Other pressing questions need to be addressed by the TEEBAgriFood study and similar explorations. How can we escape our massive dependence on fossil fuels to produce nitrogen fertilizer and how could we enhance the natural nitrogen cycle? How could cattle feed be altered to reduce methane production from livestock without putting undue stress on land needed for food crops? How can we increase fish protein in the diet without exhausting ocean stocks and endangering inland aquatic ecosystems? These and many other related questions must be looked at in a systemic, integrated way.

\section{WHAT NEXT?}

These information gaps need plugging if we are to make the transition to sustainable agrifood systems that nourish, provide energy, damage neither health nor environment, and support equitable access to resources. Extending the initial TEEBAgriFood evaluations will require the synthesis of a vast body of experience and learning from numerous practitioners in policy, farming and agribusiness. We hope to engage this wider community starting now through a call for interest to authors over the next two years (see go.nature.com/2frwqih).

To catalyse further research by others we will publish a series of studies that aim to explain and quantify the externalities associated with food systems and what can be done to reform them. To shift perspectives among consumers, business leaders and policymakers, we plan a raft of engagement exercises.

We call on researchers and practitioners who are as concerned as we are about the failings of today's agri-food systems to help us evaluate the alternatives. Our common goal should be to deliver safe and nutritious food to all, while respecting the communities and the fragile lands that nurture much of what we eat.

Pavan Sukhdev is a Goodwill Ambassador for the United Nations Environment Programme, founding trustee of GIST India, and former study leader of The Economics of Ecosystems and Biodiversity (TEEB). Peter May is professor of development, agriculture and society at the Federal Rural University of Rio de Janeiro, Brazil, a past president of the International Society for Ecological Economics, and a member of the Project Steering Committee for TEEBAgriFood. Alexander Müller is a former assistant director-general for agriculture at the Food and Agriculture Organization of the United Nations, study leader of the TEEBAgriFood Project, and managing director of TMG - Töpfer, Müller, Gassner, a sustainability think tank. e-mail:pavan@gistadvisory.com

1. Food Systems and Natural Resources (UNEP, 2016)

2. Global Nutrition Report: From Promise to Impact (Int. Food Policy Res. Inst., 2016).

3. The State of Food Insecurity in the World 2015 (FAO, 2015).

4. Alexandratos, N. \& Bruinsma, J. 'World Agriculture Towards 2030/2050: the 2012 revision' ESA Working Paper No. 12-03 (FAO, 2012).

5. Lowder, S. K., Skoet, J. \& Singh, S. 'What do we really know about the number and distribution of farms and family farms worldwide?' ESA Working Paper No. 14-02 (FAO, 2014).

6. International Labour Organization World Employment Social Outlook: Trends 2015 (International Labour Office, 2015).

7. The Cost of Fire: An Economic Analysis of Indonesia's 2015 Fire Crisis (World Bank, 2016). 